Adv Chronic Kidney Dis. 2010 May ; 17(3): e1-e16. doi:10.1053/j.ackd.2010.01.005.

\title{
Evaluation and Management of Pain in Autosomal Dominant Polycystic Kidney Disease
}

\author{
Marie C. Hogan and Suzanne M. Norby \\ Department of Medicine, Division of Nephrology and Hypertension, Mayo Clinic, Rochester, MN.
}

\begin{abstract}
Transient episodes of pain are common in autosomal dominant polycystic kidney disease (ADPKD). A small fraction of patients have disabling chronic pain. In this review, we discuss the etiologies of pain in ADPKD; review how ADPKD patients should be assessed; and discuss medical, surgical, and other management options.
\end{abstract}

\section{Keywords}

Polycystic kidney; Autosomal dominant; Flank pain; Polycystic kidney disease complications

Pain is a common symptom in patients with autosomal dominant polycystic kidney disease, often occurring early during the course of the disease and leading to the diagnosis. ${ }^{1-7}$ It can be managed effectively in most patients, but a minority of patients develop chronic pain that limits their ability to function; causes sleep disturbance, fatigue, anxiety, and depression; and negatively affects social relationships. 8,9

Health care providers often fail to discuss pain during encounters with patients with ADPKD, leading to suboptimal management. ${ }^{2,9}$ Understanding the spectrum of causes of pain in ADPKD helps to guide diagnostic evaluations and specific treatments. Recent studies have sought to characterize pain in ADPKD both quantitatively ${ }^{2}$ and qualitatively. ${ }^{9}$ This review focuses on the causes of ADPKD-related pain and discusses management options.

Patients with ADPKD report pain located in the low back (71\%), abdomen (61\%), head (49\%), chest (30\%), and legs (27\%), often with radicular features. ${ }^{2}$ Although cyst hemorrhage, nephrolithiasis, and urinary tract infection are often associated with acute episodes of pain, the exact cause of chronic flank pain cannot always be determined. ${ }^{7,10}$ Chronic pain related to cysts has been attributed to traction of the renal pedicle, distension of the capsule, and compression of nearby structures. ${ }^{2}$ Sometimes, the patient may be able to indicate the location of pain with 1 finger, but frequently the pain is more diffuse. It can be described as "razor sharp," knife-like, dull, aching, cramping, or as a "fullness," generally lasting for hours to days and rated 4 to 5 out of 10 on a visual analog scale. ${ }^{2,9}$ Exacerbations

C 2010 by the National Kidney Foundation, Inc. All rights reserved.

Address correspondence to Marie C. Hogan, MD, PhD, Mayo Clinic, 200 First Street SW, Rochester, MN 55905.

Hogan.marie@mayo.edu. 
occur unpredictably, several times per day or per week or only a few times a month. The inability to anticipate the onset of episodes or exacerbations of pain in ADPKD can cause patients to worry and to limit social activities. ${ }^{9}$ A small study using the Short-Form 36 Health Status Questionnaire (SF-36), a self-report tool to assess physical and mental wellbeing, showed that patients reporting use of pain medication within the previous month had lower scores on the Physical Component Summary than those who did not report any recent pain medication use. ${ }^{11}$

\section{Pathogenesis}

The detection of kidney pain relies on input from sympathetic, parasympathetic, and sensory nerves. ${ }^{12}$ Chronic pain, regardless of the initial precipitating factor, is likely maintained by aberrant activity of sensory and autonomic neurons innervating the kidney, renal pelvis, and ureters (Fig 1). The sympathetic nerves supplying the kidneys originate in spinal cord segments $\mathrm{T} 10$ to $\mathrm{L} 1$ and travel via white rami to the paravertebral ganglia. ${ }^{12,13}$ The sympathetic nerves travel via the lesser splanchnic nerves from the T10 and 11 thoracic paravertebral ganglia to the synapse at the ipsilateral aorticorenal and celiac ganglia (Fig 1). From the 12th thoracic paravertebral ganglion, nerves travel via the least splanchnic nerve to the synapse either in the aorticorenal ganglion or in the renal plexus. The first lumbar splanchnic nerve and the postganglionic sympathetic nerves from the aorticorenal and celiac plexi synapse in the renal plexus. The parasympathetic inner-vation originates from the vagus nerve. These parasympathetic nerves traverse through the celiac plexus or pass directly to the renal plexus. ${ }^{14}$ Sensory renal nerves travel via the renal plexus, splanchnic nerves, thoracic sympathetic ganglia, T10-12 spinal nerves, and spinal cord dorsal horn neurons. Extensive cross-connection with innervation to other visceral structures explains the complex patterns of referred pain in some patients.

\section{Diagnosis and Evaluation}

Patients can complain of abdominal, back, and flank pain, all of which can be severe and require evaluation, in addition to the sensation of flank heaviness, which is not a "pain" as such. Kidney and nonkidney sources of pain not related to cystic disease must be considered; for example, abdominal wall hernias, colon diverticulitis, and possibly abdominal aneurysms, which occur with increased frequency in ADPKD patients.

\section{Assessment of Pain in ADPKD}

A detailed history should be obtained focusing pain location, duration, associated symptoms and relieving factors. The history will frequently help to identify whether pain relates directly or indirectly (eg, mechanical back pain related to organomegaly) to the cystic disease or whether is a manifestation of extrarenal associations of the disease. 


\section{Kidney Pain}

\section{Acute}

Cyst hemorrhage, urinary tract infection, and nephrolithiasis are common causes of transient pain in ADPKD. The frequency of cyst hemorrhage, gross hematuria, and nephrolithiasis correlate directly with the size of the kidneys. ${ }^{15}$

\section{Cyst Hemorrhage}

Pain caused by cyst hemorrhage is very common and reported as sharp, localized, and sudden in onset. It is thought that the pain is caused by an acute expansion in the cyst and distension of the renal capsule. ${ }^{4}$ Cyst hemorrhage is frequently associated with gross hematuria and passage of clots may be associated with renal colic. Occasionally subcapsular and retroperitoneal hemorrhage or hemoperitoneum may occur. ${ }^{16,17}$ Vascular endothelial growth factor produced by the cystic epithelium promotes angiogenesis, which increases the risk of hemorrhage into cysts and gross hematuria. Symptomatic episodes probably underestimate the frequency of cyst hemorrhage because more than $90 \%$ of patients with ADPKD have cysts that are hyper-dense (on computed tomography [CT] scan) or high signal (on magnetic resonance imaging [MRI]), indicative of blood or high protein content. Most hemorrhages will resolve within 2 to 7 days. If hematuria persists longer than 1 week or if the initial episode occurs after the age of 50 years, investigation to exclude neoplasm should be undertaken. Combined unenhanced and contrast-enhanced CT scan may be required (when kidney function permits) to make a correct diagnosis and differentiate among the various complications affecting patients with ADPKD. ${ }^{18,19}$ Patients should be forewarned of pain episodes associated with cyst hemorrhage by their physicians and advised on what measures to take (see management).

\section{Cyst Infection and Pyelonephritis}

Urinary tract infections occur more frequently in women than men. Patients with ADPKD are at risk for acute pyelonephritis and for cyst infections. When there is suspicion of urinary tract infection in a patient with ADPKD, urine for Gram stain and culture should be immediately obtained and appropriate antibiotic management quickly instituted. Because genitourinary instrumentation is associated with an increased risk, prophylactic antibiotics are indicated when this instrumentation is necessary. Patients with upper urinary tract infections usually present with fever, leukocytosis, and flank pain. Acute pyelonephritis and cyst infection may be different to separate. Failure to respond to or recurrence of symptoms after an appropriate course of antibiotics should suggest a diagnosis of cyst infection. Cyst hemorrhage can also present with flank pain and fever but usually without leukocytosis. Negative urine and blood cultures do not entirely exclude cyst infection. In the appropriate clinical setting, cyst aspiration and culture of complex cysts detected by imaging studies may be indicated. Diagnostic criteria have recently been proposed for both kidney and hepatic cyst infection: presence of all of the following: fever (temperature $>38.5^{\circ} \mathrm{C}$ for $>3$ d), abdominal pain (particularly a palpable area of renal or liver tenderness), increased Creactive protein $(\mathrm{C}$-reactive protein $>50 \mathrm{mg} / \mathrm{L}$ ), and the absence of any significant recent intracystic bleeding (based on the results of an abdominal computed tomography [CT] scan) or other causes of fever. ${ }^{20}$ Kidney (and liver) ultrasound data should be considered positive 
if debris with a thick wall and/ or a distal acoustic enhancement is detected in at least one cyst. Kidney CT scan and magnetic resonance imaging (MRI) data are considered positive when enhanced wall thickening and/or perilesional inflammation is detected in at least 1 cyst. ${ }^{20}$ Diffusion-weighted MRI or nuclear imaging (67-Ga or 111-In-labeled leucocyte scans) can also be useful, but false-negative and -positive results are possible with the latter techniques. ${ }^{20,21}$ Positron emission tomography scans may be helpful particularly for infected liver cysts. ${ }^{20,22,23}$

\section{Nephrolithiasis}

Kidney stones occur in $20 \%$ ADPKD patients and often present with renal colic. ${ }^{24-26}$ Stones are usually made of calcium oxalate or uric acid. Urinary stasis secondary to the distorted renal anatomy might also play a part and metabolic factors include decreased ammonia excretion, low urinary $\mathrm{pH}$, and low urinary citrate concentration. Stones can be difficult to differentiate from cyst wall and parenchymal tissue calcification. Patients with larger kidneys are more prone to develop stones. ${ }^{19}$ To rule out obstruction (eg, because of large cysts near the pelvis or calculus), CT imaging with contrast (where feasible) can be most informative. ${ }^{18}$ Early consultation with urology or interventional radiology for management with relief of obstruction should be considered.

\section{Renal Cell Carcinoma}

Renal cell carcinoma is a rare cause of pain in ADPKD. It occurs no more commonly in ADPKD patients than in the general population. However, it may present at an earlier age with frequent constitutional symptoms and a higher proportion of sarcomatoid, bilateral, multicentric, and metastatic tumors. ${ }^{27}$ The presence of a solid mass on ultrasonography, speckled calcifications on CT, contrast enhancement, tumor thrombus, or regional lymphadenopathy should raise concern for carcinoma.

\section{Chronic Kidney Pain}

The definition of chronic pain is daily pain lasting more than 4 to 6 weeks. Some authors prefer three months to be the dividing line between acute and chronic pain. Pain related directly to a specific cyst tends to be a steady nagging discomfort, with the standing position and walking exacerbating the discomfort. ${ }^{1}$ Patients can often localize the pain with 1 finger, and the location tends to be most frequently identified as the anterior abdominal area more so than localized back pain. The area pinpointed may not readily correlate with the largestsized cysts seen on imaging.

Often, pain begins with an acute episode and persists as chronic kidney pain after the eliciting cause has been treated and resolved, suggesting sensitization. On other occasions, it develops gradually and becomes severe over several years. There is little relation between the appearance of the kidneys and the severity of chronic pain: patients with moderate or even mild cystic disease may still have disabling pain. This condition is very frustrating to patients and physicians because extensive laboratory testing of the serum and urine and exhaustive imaging studies fail to provide evidence for associated findings to explain the 
pain. Careful assessment is needed to identify non-renal pain and evaluation by a physical medicine physician can be helpful to exclude musculoskeletal causes.

\section{Early Satiety}

Sometimes a large kidney cyst compressing the greater curvature of the stomach and /or duodenal loop can lead to early satiety.

\section{Liver-related Pain}

Hepatic cysts have been detected by MRI in 94\% of patients between the ages of 35 and 46 although liver function remains preserved. ${ }^{28}$ Most patients have no symptoms from these. Patients with marked hepatomegaly may experience a sensation of heaviness, dull ache, mechanical low back, and gastrointestinal symptoms (Figs 3,4). ${ }^{29}$ Episodes of cyst hemorrhage, rupture, torsion, and infection may be associated with acute episodes of pain. Rarely, patients may develop symptoms from compression of vessels (hepatic venous outflow obstruction, compression of the inferior vena cava or portal vein) or bile ducts. ${ }^{10,27}$

\section{Pancreas-related Pain}

It is extremely unusual to have pain because of pancreatic disease. When it occurs, it is caused by pancreatic duct obstruction causing pancreatitis. Pancreatic cysts can be detected by ultrasound in $5 \%$ to $9 \%$ of patients ${ }^{30,31}$ although it may be closer to $19 \%$ by MRI. ${ }^{10,32,33}$ An intraductal papillary mucinous neoplasm has been reported in patients with ADPKD. ${ }^{34}$

\section{Medical Management of Kidney Pain in ADPKD}

\section{Cyst Hemorrhage}

In the majority of patients, episodes of pain associated with cyst hemorrhage and gross hematuria are transient and resolve spontaneously. Patients should be advised to avoid aspirin and physical activities, and symptoms may necessitate time off work, use of acetaminophen or propoxyphene (Darvocet, Aaipharma, Wilmington, NC, USA, Table 1) in scheduled doses until the pain subsides, and staying well hydrated. Hypertension should be strictly controlled. If the pain is severe or if gross hematuria is persistent or recurrent, more thorough evaluation including CT scans or MRI is indicated. Hospitalization may be necessary for pain control or for close observation when the hemorrhage is severe, extends into the retroperitoneal space, or causes urinary tract obstruction by clots. Rarely, interventions to stop the hemorrhage (embolization or surgery) may be necessary.

\section{Cyst infection}

The efficacy of antibiotic treatment and infection eradication is defined by the disappearance of fever, normalization of C-reactive protein levels, and at least 2 negative blood and/or urine cultures (these criteria also apply for hepatic cyst infection). ${ }^{20}$ If unresponsive to these measures, percutaneous or surgical drainage should be considered. 


\section{Nephrolithiasis}

Extracorporeal shock wave lithotripsy can be performed safely in selected patients with ADPKD; however, the presence of residual fragments in $\sim 50 \%$ of patients is higher than that in patients without ADPKD. ${ }^{25,26}$

\section{Management of Acute Liver Pain}

\section{Hepatic Cyst Infection}

Studies have shown that drainage and antibiotics prove more efficacious than antibiotics alone in hepatic cyst infections (Fig 3), and another larger study confirmed that in the case of large-diameter $(>5 \mathrm{~cm})$ infected cysts, early drainage is necessary because antibiotics alone do not usually resolve the infection. ${ }^{20,35}$

\section{Management of Chronic Kidney Pain}

\section{Noninvasive Techniques}

There have been no formal studies looking at these modalities in PKD, and they are a fertile area for future research. Because very limited knowledge exists on the underlying physiology of visceral and somatic pain syndromes and their pharmacologic management, conservative measures are suggested first (Fig 2). These include the use of physical measures such as ice, heat, whirlpool, massage, and the Alexander technique. ${ }^{36,37}$

\section{Alexander Technique}

Training in the Alexander technique (by a trained teacher) provides an individualized approach designed to develop skills for self-care that help people recognize, understand, and avoid poor habits affecting postural tone and neuromuscular coordination. The technique involves continuous assessment of individual patterns of habitual musculoskeletal posture with special attention to the release of unwanted head, neck, and spinal muscle tension, which is guided by verbal instruction and hand contact. The goal is to allow decompression of the spine and improve posture. ${ }^{36}$

\section{Transcutaneous Electrical Nerve Stimulation}

There is good evidence that TENS may reduce the perception of nociceptive stimuli because most dorsal horn cells with renal inputs have the concomitant somatic inputs. TENS electrodes placed on the somatic receptive fields of neurons on the skin reduced responsiveness to nociceptive stimuli and decreased the dorsal horn cell responsiveness to C-fiber direct electrical stimulation to about $39 \%$ of control in cats. ${ }^{38}$ In these studies, TENS decreased the dorsal horn cell responsiveness to C-fiber direct electrical stimulation to $39 \%$ of control and dorsal horn cell responsiveness to ureteral occlusion decreased to $38 \%$ of control. Again, in this model, with renal artery occlusion, the dorsal horn cells were only $46 \%$ as responsive with TENS use compared with controls. Bajwa et $\mathrm{al}^{1}$ found that the intermittent use of a TENS unit can often help alleviate symptoms especially in patients with chronic dull aching pain. They suggested that a trial can be given for 2 weeks, and if found effective it can be used long-term with virtually no side effects. It has also been found to be helpful in managing renal colic. ${ }^{39}$ 


\section{Nonopioid Analgesia}

Acetaminophen has been used as a first-line pain medication for over 50 years and is safe in patients with renal impairment. Its mechanism of action is in the central nervous system. Because of the potential nephrotoxicity of nonsteroidal anti-inflammatory drugs, opioid agents are often used as the next step for patients with ADPKD who do not achieve adequate pain control with acetaminophen.

\section{Opioid Analgesia}

Opioids have been regarded for centuries as among the most effective drugs for the treatment of pain, but in the 21 century prescribers should be concerned not only about their obligation to address and adequately treat pain but also with the potential for patients to develop adverse effects, habituation, and addiction. ${ }^{40}$ Patients should be informed about possible adverse effects and enter into an informed agreement for treatment with opioid analgesics. ${ }^{41}$ In general, short-acting opioids (Table 1) are useful for initial titration and control of pain. Regardless of which opioid regimen is used, physicians should assess the level of pain and function before and after initiating opioid therapy as well as repeatedly evaluate for the potential of misuse or abuse of these agents. ${ }^{41}$

There are currently no guidelines available on the use of opioid medication in people with chronic kidney pain. However, the American Society of Pain physicians recommend that the effectiveness of long-term opioids in reducing chronic noncancer pain and improving functional status for 6 months or longer is variable. ${ }^{42,43}$ The best evidence for efficacy applies to transdermal fentanyl and sustained-release morphine (level II-2), whereas for oxycodone the level of evidence is II-3 and the evidence for hydrocodone and methadone is level III. Because there is also significant evidence of misuse and abuse of opioids, we tend to involve a specialist in pain management in the assessment of these patients because they are at risk of becoming disabled by pain and are treated with increasing doses of antidepressant and opioid medications that have significant side effects and potential for toxicity and addiction. Also, they may be subjected to multiple invasive procedures, such as spinal cord stimulation, cyst aspirations, and fenestration surgery, which have only shown potential benefit in uncontrolled studies (Table 2).

\section{Tramadol}

Tramadol (Ultram, Ortho-McNeil-Janssen Pharmaceuticals, Titusville, NJ, USA) is particularly effective for moderate pain, and we tend to use this if acetaminophen is ineffective alone or in combination with acetaminophen (Ultra-cet, Ortho-McNeil-Janssen Pharmaceuticals, Titusville, NJ, USA). Once adequate pain control is achieved, consideration may be given to switching to long-acting opioids (Table 1), which can provide less erratic analgesia and improve medication adherence because less frequent dosing is needed. ${ }^{44}$

\section{Adjuvant Analgesics}

Adjuvant analgesics should also be considered for ADPKD patients with chronic kidney pain, specifically clonidine, gabapentin, or pregabalin. ${ }^{45}$ 


\section{Gabapentin}

Although there have been no studies of this medication in ADPKD, gabapentin (Neurontin, Pfizer, New York, NY) has been shown to be a useful medication in the treatment of genitourinary pain. It has been successfully used in chronic genitourinary pain at a mean dose of $1,200 \mathrm{mg} / \mathrm{d}$ of gabapentin (range, 300-2,100 mg). Some patients reported subjective improvement of their pain, but others showed no improvement. The most common adverse effects were dizziness and drowsiness. ${ }^{45}$ Gabapentin should be used cautiously, requiring dose reduction or interval extension in patients. Suggested dosing is as follows: reduced kidney function, and monitoring of drug levels is indicated for patients. Suggested dosing is as follows: $\mathrm{CrCl}>60 \mathrm{~mL} / \mathrm{min}, 900$ to $3,600 \mathrm{mg} / \mathrm{d}$; $\mathrm{CrCl} 30$ to $59 \mathrm{~mL} / \mathrm{min}, 400$ to 1,400 $\mathrm{mg} / \mathrm{d}$; $\mathrm{CrCl} 15$ to $29 \mathrm{~mL} / \mathrm{min}, 200$ to $700 \mathrm{mg} / \mathrm{d}$; and $\mathrm{CrCl} 15 \mathrm{~mL} / \mathrm{min}, 100$ to $300 \mathrm{mg} / \mathrm{d}$. For patients with $\mathrm{CrCl} \leq 15 \mathrm{~mL} / \mathrm{min}$, the daily dose should be decreased in proportion to creatinine clearance. ${ }^{46}$

\section{Pregabalin}

There are no studies of its effectiveness in patients with chronic kidney pain, but it has been shown to be effective in neuropathic pain syndromes. Pregabalin should be used cautiously, requiring dose adjustment in patients with reduced kidney function. Dose adjustment should be considered for patients with $\mathrm{CrCl}<60 \mathrm{~mL} / \mathrm{min}$. A $50 \%$ reduction in pregabalin daily dose is recommended for patients with CrCL between 30 and $60 \mathrm{~mL} / \mathrm{min}$ compared with those with $\mathrm{CrCl}>60 \mathrm{~mL} / \mathrm{min}$. Daily doses should be further reduced by $\sim 50 \%$ for each additional 50\% decrease in $\mathrm{CrCl}$. Pregabalin is highly cleared by hemodialysis.

Supplemental pregabalin doses may be required for patients on chronic hemodialysis treatment after each hemodialysis treatment to maintain steady-state plasma pregabalin concentrations within desired ranges.

\section{Spinal Cord Stimulation}

Neuromodulation of the spinal column by implanting electrodes in the epidural space is another method used for chronic pain control. This is an invasive procedure and requires a long-term implantation of a device and will preclude future MRI studies. The principle of action is probably similar to TENS but has the additional benefit of more central intense effects and also avoids the cutaneous discomfort associated with a TENS unit. Before the permanent stimulator is implanted, a trial stimulator electrode is used for a few days to assess the beneficial effects. For moderate to severe pain, it can be a very useful nonpharmacologic treatment option (Fig 2).

\section{Complementary Medicine}

\section{Acupuncture}

There are no studies of acupuncture in polycystic kidney disease, but many patients have mechanical low back pain because of their large kidneys and may benefit from acupuncture (Fig 2). Collectively, a number of recent trials provide strong and consistent evidence that real acupuncture needling using the Chinese meridian system is no more effective for chronic back pain than various purported forms of sham acupuncture and that both real and sham acu-puncture, however, appear superior to usual care. ${ }^{47-49}$ Individualized acupuncture, 
standardized acupuncture, and simulated acupuncture therapies compared with usual care have been shown to have beneficial and persisting effects on chronic back pain and provide clinically meaningful improvements in function. Medication usage has also been reported to decrease significantly with this treatment. MRI studies have shown that superficial and deep needling of an acupuncture point elicited similar blood oxygen level-dependent responses. ${ }^{50}$

\section{Surgical Approaches}

\section{Kidney Pain}

Kidney cyst(s) aspiration-Cyst aspiration, (Fig 5), which is sometimes accompanied by sclerosis is the least invasive among the various surgical interventions for pain related to ADPKD. Although aspiration may successfully relieve pain in the short-term, only about one third of patients may remain pain free at 18 months. ${ }^{51}$

Surgical Fenestration of Kidney Cysts-In cases in which cysts are large and cause marked distortion of the kidney and compression of the surrounding tissues, surgical cyst fenestration can provide symptomatic relief. Although patients undergoing surgical decompression may obtain immediate pain relief in $85 \%$ to $90 \%$, which decreases to $62 \%$ to $67 \%$ within 2 years, and experience improved blood pressure control, the technique has partial chance of success in providing long-term pain control. ${ }^{1,2,7,14,52-54}$

Renal Denervation-Renal denervation also yields favorable results for pain control and may be performed laparoscopically ${ }^{55-57}$ with or without nephropexy or thoracoscopically. ${ }^{58}$ In 2001, a bilateral laparoscopic renal denervation procedure was first reported in a 41-yearold man with ADPKD who had become completely disabled because of kidney pain. ${ }^{57}$ Using a modified laparoscopic living-donor nephrectomy incision approach, nerve fibers of the renal and intermesenteric plexi were severed along the anterior surface of the aorta and the periarterial nervous tissue on the right renal artery was divided (Fig 1). Upon initial follow-up, the patient had 2 of 10 pain, but no information on long-term outcome is available. In 2004, using a thoracoscopic approach for splanchnicectomy (renal denervation) surgery, a left kidney denervation was performed in a 47-year-old woman with intractable pain and full disability. ${ }^{58}$ Sensory afferents for the kidneys travel via the splanchnic nerves (greater, lesser, and least splanchnic nerves), and in this procedure the sympathetic chain and roots of the splanchnic nerves were selectively removed (Fig 1) from the level of the first root of the greater splanchnic nerve to the diaphragmatic recess. In this patient, postoperative pain resolved after 3 months, and she remained pain free at 1 year. Identification of the different roots of the splanchnic nerves (Fig 1) is considered less difficult by this approach compared with the method used by Valente and colleagues, ${ }^{57}$ who used an abdominal laparoscopic surgery approach and handled the renal arteries to sever the nerve supply to both kidneys. Complete removal of the nerves is recommended, and this may be the reason why this procedure is successful in alleviating pain compared with previous reports in which the nerve was severed but not completely removed; instead inadequate excision of 1- to 2-cm segments of nerves, division with electrocautery, transection of the main trunks of the nerves, or splanchnicolysis by thermocoagulation was done. The complete removal, using sharp dissection, monopolar or bipolar electrocautery, or 
ultrasonic dissection is necessary to prevent re-nervation and accounts for poor long-term results of this procedure for other indications ${ }^{59,60}$ Although Chapuis and colleagues ${ }^{58}$ reported a unilateral procedure, they suggested that a bilateral thoracoscopic approach could be performed in 1 procedure. Recently, another small series reported 4 adolescent ADPKD patients who underwent laparoscopic denervation of 5 kidneys by abdominal transperitoneal approach, with excellent intermediate results. ${ }^{56}$ This group performed nephropexy because the entire kidney was circumferentially dissected from the surrounding tissue as well as the hilum. The circumferential dissection is intended to eliminate any potential nerves not coursing through the hilum and participating in innervation. ${ }^{56}$ We have performed thoracoscopic renal denervation for intractable renal pain in 10 patients (Clinicaltrials.gov NCT00571909). ${ }^{61}$ Six of these patients have enrolled in a 2-year prospective study to evaluate the impact of this procedure on pain control, opioid use, quality of life, and renal blood flow (measured by MRI) and renal function (by iothalamate glomerular filtration rate). All had chronic pain requiring opioid analgesics for more than 6 months before enrollment. All 10 reported that their pain was immediately different and less intense after the surgery. Pain treatment satisfaction at 3 months compared with baseline improved in the 6 study patients. ${ }^{61}$ We prefer this approach to an abdominal approach because there is no handling of the renal arteries and hence very low likelihood of developing a subsequent renal artery stenosis (as occurred in the case of the patient who had the abdominal laparoscopic approach (Dr WM Bennett, personal communication, June 2007) ${ }^{57}$ (Table 2).

Nephrectomy - Nephrectomy is reserved for patients who fail other methods of pain control. Although some patients seek nephrectomy before dialysis commencement or ESRD, we do not advocate this approach unless patients have at least stage IV CKD. Either unilateral or bilateral nephrectomies may be performed, usually when one or both kidneys are functioning at a very low level. In general, the removal of large polycystic kidneys may be safely accomplished via laparoscopy with fewer complications, decreased postoperative pain, and a better cosmetic result compared with open nephrectomy. ${ }^{62}$ Occasionally, operative complications during laparoscopic nephrectomy will obligate conversion to an open procedure; this is more likely when renal volume is above $3500 \mathrm{~mL} .{ }^{63}$ Options for patients who are candidates for kidney transplantation and after transplantation are dealt with in a separate section written by Dr Perrone.

Transcatheter Arterial Embolization-When there is progressive abdominal distention and discomfort because of large kidneys, another approach that has been used has been renal transcatheter arterial embolization (TAE) using intravascular coils. Renal arteriography is required to identify the renal arteries at a proximal location. The approach initially described by Ubara and colleagues ${ }^{64,65}$ has changed over time, and this procedure is suitable in a minority of patients who have reached ESRD, are unstable, or are a poor surgical candidate (for nephrectomy). Initially, stainless steel coils were placed into the renal arteries and were then advanced into the arteries. Subsequently, platinum microcoils were used to obstruct peripheral renal artery branches. If this is ineffective in reducing renal volume, a third procedure of application of a gelatin sponge close to the platinum microcoil in the smaller renal arterial branches that could not be obstructed by microcoils is used. A spinal epidural was required for pain control in the majority of patients. At least 30 platinum microcoils 
were required in most of the cases. Serious complications were not seen after this treatment although such minor complications as fever and flank pain were observed within the first week after the procedure. ${ }^{64,65}$ This procedure is capable of reducing kidney volume up to $\sim 50 \%$ at 12 months compared with preintervention volumes.

\section{Liver Surgery: Partial Hepatic Reduction and Liver Cyst Fenestration Surgery}

- Surgical interventions may also be considered for pain related to massive PCLD although indications for and outcomes of hepatic volume reduction with partial hepatic resection and/ or cyst fenestration have not been characterized until recently. In a series of 141 patients from the Mayo Clinic who underwent partial hepatectomy with cyst fenestration of the hepatic remnant (88\%), cyst fenestration alone (7\%), and orthotopic liver transplantation $(5 \%)$, the indication for surgery in $93 \%$ of patients was the presence of symptoms, including pain, severe enough to negatively impact quality of life. Thorough preoperative imaging and assessment at a center with experience in these procedures is mandatory to select appropriate surgical candidates as well as to determine which procedure is likely to yield the best overall outcome (Fig 3). Encouragingly, 75\% of long-term survivors report improved or normalized performance status, and bodily pain scores on the SF-36 questionnaire appear similar to general population norms. ${ }^{66} \mathrm{In}$ another series Que and colleagues ${ }^{67}$ reported a $~ 62 \%$ mean reduction in liver volume with combined liver resection and cyst fenestration surgery.

TAE-TAE, which has been used in treating hepato-cellular carcinoma, has been reported in a small series of patients with symptomatic polycystic liver disease (PCLD) to substantially decrease ( $\sim 20 \%$ ) both total liver and cyst volume. ${ }^{68}$ Normal liver generally shows hepatic arterial and portal venous branches that course in parallel in the same anatomic segment (liver is divided anatomically into 7 segments). However, in polycystic livers, hepatic arteries and portal veins course in a different fashion; almost all hepatic arterial branches are well developed, whereas portal venous branches in hepatic segments are replaced by multiple cysts. Using local anesthesia, the interventional radiologist superselectively targets hepatic arterial branches supplying hepatic regions to minimize damage to the remaining intact liver, and the majority of patients underwent embolization of 2 to 5 segments using platinum micro-coils. ${ }^{68}$ In experienced hands, TAE appears to be useful in treating symptomatic PLD in selected ADPKD patients with few serious adverse effects; however, the procedure has only been reported to have been used routinely in Japan and Korea. ${ }^{68,69}$ It may be particularly useful in symptomatic patients deemed unfit for any other type of surgical procedure. Common side effects include fever, nausea, vomiting, and epigastric pain. Contrast is required for this procedure, thus limiting its utility in patients with advanced CKD.

\section{Conclusions}

There are multiple causes of pain in individuals with ADPKD, and each patient needs careful evaluation. Significant improvements in medical, radiologic, and surgical approaches to pain management have occurred in ADPKD and PCLD in the last 5 years. More procedures are now available to physicians involved in managing ADPKD patients with pain. 


\section{Future Directions}

In the field of pain research, it is likely there will be significant advances in the identification and validation of urine biomarkers that correlate with kidney pain intensity using as-says that are minimally invasive and easy to perform at the bedside. ${ }^{70}$ These could be tested in ADPKD patients with chronic pain, permitting noninvasive monitoring of these patients. Such biomarkers are likely to be small peptides readily detectable in urine by mass spectroscopy (eg, substance $\mathrm{P}$, calcitonin gene-related peptide, or prostaglandins). The identification of such biomarkers are likely to enhance understanding of the molecular pathways involved in chronic kidney pain pathways and may provide important therapeutic targets. $^{71}$

In order to prospectively study the problem of pain in ADPKD pain questionnaires are being used in the HALTstudy, a multicenter, randomized, double-blind, placebo-controlled interventional study evaluating conventional versus intensive blood pressure control in 1018 hypertensive ADPKD patients. ${ }^{72}$ These data gathered will provide the largest database of information to date on pain patterns in ADPKD patients and may provide the basis for development of surrogate end points for pain monitoring in this group helping to identify the important minority of ADPKD patients with severe pain and permit validation of pain biomarkers.

Future studies are needed to evaluate the utility of emerging end organ interventions in the management of ADPKD patients with chronic kidney and liver pain. These studies ideally should include monitoring of therapeutic pain biomarker based end points as they become available.

\section{References}

1. Bajwa ZH, Gupta S, Warfield CA, Steinman T. Pain management in polycystic kidney disease. Kidney Int. 2001; 60:1631-1644. [PubMed: 11703580]

2. Bajwa ZH, Sial KA, Malik AB, Steinman TI. Pain patterns in patients with polycystic kidney disease. Kidney Int. 2004; 66:1561-1569. [PubMed: 15458452]

3. Dalgaard OZ. Bilateral polycystic disease of the kidneys: A follow-up of two hundred and eightyfour patients and their families. Acta Med Scand. 1957; 328(suppl):1-255.

4. Gabow PA. Autosomal dominant polycystic kidney disease-more than a renal disease. Am J Kidney Dis. 1990; 16:403-413. [PubMed: 2239929]

5. Grantham JJ. Renal pain in polycystic kidney disease: When the hurt won't stop. J Am Soc Nephrol. 1992; 2:1161-1162. [PubMed: 1591356]

6. Iglesias CG, Torres VE, Offord KP, Holley KE, Beard CM, Kurland LT. Epidemiology of adult polycystic kidney disease, Olmsted County, Minnesota: 1935-1980. Am J Kidney Dis. 1983; 2:630_ 639. [PubMed: 6846334]

7. Segura, JW.; King, BF., Jr; Jowsey, SG.; Martin, P.; Zince, H. Chronic pain and its medical and surgical management in renal cystic diseases. In: Torres, VE.; Watson, ML., editors. Polycystic Kidney Disease. Oxford University; New York, NY: 1996. p. 462-480.

8. Clarke KA, Iphofen R. A phenomenological hermeneutic study into unseen chronic pain. Br J Nurs. 2008; 17:658-663. [PubMed: 18563008]

9. Heiwe S, Bjuke M. "An evil heritage": Interview study of pain and autosomal dominant polycystic kidney disease. Pain Management Nursing. 2009; 10:134-141. [PubMed: 19706350]

10. Torres VE, Harris PC, Pirson Y. Autosomal dominant polycystic kidney disease. Lancet. 2007; 369:1287-1301. [PubMed: 17434405] 
11. Rizk D, Jurkovitz C, Veledar E, et al. Quality of life in autosomal dominant polycystic kidney disease patients not yet on dialysis. Clin J Am Soc Nephrol. 2009; 4:560-566. [PubMed: 19261830]

12. Ansell, J.; Gee, W.; d, BJ. Diseases of the kidney and ureter. In the management of pain. In: Bonica, J.; J, B., editors. The management of pain. 2nd edition. Vol. 2. Lea \& Febiger; Philadelphia, PA: 1990. p. 1232-49.Lea \& Febiger: Philadelphia, PA. p. 1232-1249

13. Naidoo N, Partab P, Pather N, Moodley J, Singh B, Satyapal KS. Thoracic splanchnic nerves: implications for splanchnic denervation. J Anat. 2001; 1995:585-590. [PubMed: 11760889]

14. Brown JA, Torres VE, King BF, Segura JW. Laparoscopic marsupialization of symptomatic polycystic kidney disease. J Urol. 1996; 156:22-27. [PubMed: 8648810]

15. Bennett WM, Elzinga LW. Clinical management of autosomal dominant polycystic kidney disease. Kidney Int Suppl. 1993; 42:S74-S79. [PubMed: 8361135]

16. Ravich L, Lerman PH, Drabkin J. Ruptured renal cyst in polycystic disease. Urology. 1976; 7:60_ 61. [PubMed: 1246770]

17. Tarrass F, Benjelloun M. Acute abdomen caused by spontaneous renal cyst rupture in an ADPKD haemodialysed patient. Nephrology. 2008; 13:177-178. [PubMed: 18275508]

18. Gupta S, Seith A, Sud K, et al. CT in the evaluation of complicated autosomal dominant polycystic kidney disease. Acta Radiol. 2000; 41:280-284. [PubMed: 10866086]

19. Nishiura JL, Neves RF, Eloi SR, Cintra SM, Ajzen SA, Heilberg IP. Evaluation of nephrolithiasis in autosomal dominant polycystic kidney disease patients. Clin J Am Soc Nephrol. 2009; 4:838844. [PubMed: 19339428]

20. Sallee M, Rafat C, Zahar J-R, et al. Cyst infections in patients with autosomal dominant polycystic kidney disease. Clin J Am Soc Nephrol. 2009; 4:1183-1189. [PubMed: 19470662]

21. Yuki K, Takeshi S, Akito T. Diagnosis and localization of infected renal cyst by diffusionweighted magnetic resonance imaging in polycystic kidney disease. Int J Urol. 2009; 16:918-919. [PubMed: 19863628]

22. Bleeker-Rovers CP, de Sevaux RG, van Hamersvelt HW, Corstens FH, Oyen WJ. Diagnosis of renal and hepatic cyst infections by 18 -F-fluorodeoxyglucose positron emission tomography in auto-somal dominant polycystic kidney disease. Am J Kidney Dis. 2003; 41:E18-E21. [PubMed: 12776306]

23. Soussan M, Sberro R, Wartski M, Fakhouri F, Pecking AP, Alberini JL. Diagnosis and localization of renal cyst infection by $18 \mathrm{~F}$-fluorodeoxyglucose PET/CT in polycystic kidney disease. Ann Nucl Med. 2008; 22:529-531. [PubMed: 18670861]

24. Torres VE, Erickson SB, Smith LH, Wilson DM, Hattery RR, Segura JW. The association of nephrolithiasis and autosomal dominant polycystic kidney disease. Am J Kidney Dis. 1988; 11:318-325. [PubMed: 3354568]

25. Torres VE, Wilson DM, Hattery RR, Segura JW. Renal stone disease in autosomal dominant polycystic kidney disease. Am J Kidney Dis. 1993; 22:513-519. [PubMed: 8213789]

26. Grampsas SA, Chandhoke PS, Fan J, et al. Anatomic and metabolic risk factors for nephrolithiasis in patients with autosomal dominant polycystic kidney disease. Am J Kidney Dis. 2000; 36:53-57. [PubMed: 10873872]

27. Keith DS, Torres VE, King BF, Zincki H, Farrow GM. Renal cell carcinoma in autosomal dominant polycystic kidney disease. J Am Soc Nephrol. 1994; 4:1661-1669. [PubMed: 8011975]

28. Bae KT, Zhu F, Chapman AB, et al. Magnetic resonance imaging evaluation of hepatic cysts in early autosomal-dominant polycystic kidney disease: The Consortium for Radiologic Imaging Studies of Polycystic Kidney Disease Cohort. Clin J Am Soc Nephrol. 2006; 1:64-69. [PubMed: 17699192]

29. Vauthey JN, Maddern GJ, Blumgart LH. Adult polycystic disease of the liver. Br J Surg. 1991; 78:524-527. [PubMed: 2059797]

30. Nicolau C, Torra R, Bianchi L, et al. Abdominal sono-graphic study of autosomal dominant polycystic kidney disease. J Clin Ultrasound. 2000; 28:277-282. [PubMed: 10867665]

31. Torra R, Nicolau C, Badenas C, et al. Ultrasono-graphic study of pancreatic cysts in autosomal dominant polycystic kidney disease. Clin Nephrol. 1997; 47:19-22. [PubMed: 9021236] 
32. NiMhaille BA, Norby SM, Rosetti S, et al. Pancreatic cysts and intraductal papillary mucinous neoplasms in ADPKD. J Am Soc Nephrol. 2008; 19:126A.

33. Malka D, Hammel P, Vilgrain V, Flejou JF, Belghiti J, Bernades P. Chronic obstructive pancreatitis due to a pancreatic cyst in a patient with autosomal dominant polycystic kidney disease. Gut. 1998; 42:131-134. [PubMed: 9505899]

34. Sato Y, Mukai M, Sasaki M, et al. Intraductal papillary-mucinous neoplasm of the pancreas associated with polycystic liver and kidney disease. Pathol Int. 2009; 59:201-204. [PubMed: 19261101]

35. Telenti A, Torres VE, Gross JB Jr, Van Scoy RE, Brown ML, Hattery RR. Hepatic cyst infection in autosomal dominant polycystic kidney disease. Mayo Clin Proc. 1990; 65:933-942. [PubMed: 2198396]

36. Little P, Lewith G, Webley F, et al. Randomised controlled trial of Alexander technique lessons, exercise, and massage (ATEAM) for chronic and recurrent back pain. BMJ. 2008; 337:884.

37. Hall D. Bad backs-Uncovering the real problem: The Alexander technique sheds light on a sore situation. Lamp. 1988; 45:24-28. [PubMed: 2977211]

38. Nam TS, Baik EJ, Shin YU, Jeong Y, Paik KS. Mechanism of transmission and modulation of renal pain in cats; effects of transcutaneous electrical nerve stimulation on renal pain. Yonsei Med J. 1995; 36:187-201. [PubMed: 7618365]

39. Mora B, Giorni E, Dobrovits M, et al. Transcutaneous electrical nerve stimulation: An effective treatment for pain caused by renal colic in emergency care. J Urol. 2006; 175:1737-1741. [PubMed: 16600745]

40. Brennan F, Carr DB, Cousins M. Pain management: a fundamental human right. Anesth Analg. 2007; 105:205-221. [PubMed: 17578977]

41. Gourlay DL, Heit HA, Almahrezi A. Universal precautions in pain medicine: A rational approach to the treatment of chronic pain. Pain Med. 2005; 6:107-112. [PubMed: 15773874]

42. Chou R, Ballantyne JC, Fanciullo GJ, Fine PG, Miaskowski C. Research gaps on use of opioids for chronic noncancer pain: Findings from a review of the evidence for an American Pain Society and American Academy of Pain Medicine clinical practice guideline. J Pain. 2009; 10:147-159. [PubMed: 19187891]

43. Chou R, Fanciullo GJ, Fine PG, et al. Clinical guidelines for the use of chronic opioid therapy in chronic noncancer pain. J Pain. 2009; 10:113-130. [PubMed: 19187889]

44. Argoff CE, Silvershein DI. A comparison of long- and short-acting opioids for the treatment of chronic non-cancer pain: Tailoring therapy to meet patient needs. Mayo Clin Proc. 2009; 84:602612. [PubMed: 19567714]

45. Sasaki K, Smith CP, Chuang YC, Lee JY, Kim JC, Chancellor MB. Oral gabapentin (neurontin) treatment of refractory genitourinary tract pain. Tech Urol. 2001; 7:47-49. [PubMed: 11272678]

46. DRUGDEXÒ Evaluations. Thompson; 2010. Gabapentin In.

47. Brinkhaus B, Witt CM, Jena S, et al. Acupuncture in patients with chronic low back pain: a randomized controlled trial. Arch Intern Med. 2006; 166:450-457. [PubMed: 16505266]

48. Haake M, Muller HH, Schade-Brittinger C, et al. German Acupuncture Trials (GERAC) for chronic low back pain: randomized, multicenter, blinded, parallel-group trial with 3 groups. Arch Intern Med. 2007; 167:1892-1898. [PubMed: 17893311]

49. Cherkin DC, Sherman KJ, Avins AL, et al. A randomized trial comparing acupuncture, simulated acu-puncture, and usual care for chronic low back pain. Arch Intern Med. 2009; 169:858-866. [PubMed: 19433697]

50. MacPherson H, Green G, Nevado A, et al. Brain imaging of acupuncture: comparing superficial with deep needling. Neurosci Lett. 2008; 434:144-1449. [PubMed: 18294772]

51. Bennett WM, Elzinga L, Golper TA, Barry JM. Reduction of cyst volume for symptomatic management of autosomal dominant polycystic kidney disease. J Urol. 1987; 137:620-622. [PubMed: 2435925]

52. Lee DI, Andreoni CR, Rehman J, et al. Laparoscopic cyst decortication in autosomal dominant polycystic kidney disease: Impact on pain, hypertension, and renal function. J Endourol. 2003; 17:345-354. [PubMed: 12965058] 
53. Lifson BJ, Teichman JM, Hulbert JC. Role and long-term results of laparoscopic decortication in solitary cystic and autosomal dominant polycystic kidney disease. J Urol. 1998; 159:702-705. [PubMed: 9474129]

54. Elzinga LW, Barry JM, Torres VE, et al. Cyst decompression surgery for autosomal dominant polycystic kidney disease. J Am Soc Nephrol. 1992; 2:1219-1226. [PubMed: 1591362]

55. Casale P, Meyers K, Kaplan B. Follow-up for laparoscopic renal denervation and nephropexy for autosomal dominant polycystic kidney disease-related pain in pediatrics. J Endourol. 2008; 22:991-993. [PubMed: 18370613]

56. Resnick M, Chang AY, Casale P. Laparoscopic renal denervation and nephropexy for autosomal dominant polycystic kidney disease related pain in adolescents. J Urol. 2006; 175:2274-2276. [PubMed: 16697853]

57. Valente JF, Dreyer DR, Breda MA, Bennett W. Laparoscopic renal denervation for intractable ADPKD-related pain. Nephrol Dial Transplant. 2001; 16:160. [PubMed: 11209012]

58. Chapuis O, Sockeel P, Pallas G, Pons F, Jancovici R. Thoracoscopic renal denervation for intractable auto-somal dominant polycystic kidney disease-related pain. Am J Kidney Dis. 2004; 43:161-163. [PubMed: 14712440]

59. Leksowski K. Thoracoscopic splanchnicectomy for the relief of pain due to chronic pancreatitis. Surg Endosc. 2001; 15:592-596. [PubMed: 11591948]

60. Greenwell TJ, Peters JL, Neild GH, Shah PJ. The outcome of renal denervation for managing loin pain haematuria syndrome. BJU Int. 2004; 93:818-821. [PubMed: 15049996]

61. Hogan, M. Evaluation of Videothoracoscopic Renal Denervation for Intractable Autosomal Dominant Polycystic Kidney Disease-Related Pain. ASN; San Diego, CA: 2009.

62. Binsaleh S, Luke PP, Nguan C, Kapoor A. Comparison of laparoscopic and open nephrectomy for adult polycystic kidney disease: operative challenges and technique. Can J Urol. 2006; 13:33403345. [PubMed: 17187698]

63. Lipke MC, Bargman V, Milgrom M, Sundaram CP. Limitations of laparoscopy for bilateral nephrectomy for autosomal dominant polycystic kidney disease. J Urol. 2007; 177:627. [PubMed: 17222647]

64. Ubara Y, Katori H, Tagami T, et al. Transcatheter renal arterial embolization therapy on a patient with polycystic kidney disease on hemodialysis. Am J Kidney Dis. 1999; 34:926-931. [PubMed: 10561151]

65. Ubara Y, Tagami T, Sawa N, et al. Renal contraction therapy for enlarged polycystic kidneys by transcatheter arterial embolization in hemodialysis patients. Am J Kidney Dis. 2002; 39:571-579. [PubMed: 11877576]

66. Schnelldorfer T, Torres VE, Zakaria S, Rosen CB, Nagorney DM. Polycystic liver disease: A critical appraisal of hepatic resection, cyst fenestration, and liver transplantation. Ann Surg. 2009; 250:112-118. [PubMed: 19561475]

67. Que F, Nagorney DM, Gross JB Jr, Torres VE. Liver re-section and cyst fenestration in the treatment of severe polycystic liver disease. Gastroenterology. 1995; 108:487-494. [PubMed: 7835591]

68. Takei R, Ubara Y, Hoshino J, et al. Percutaneous trans-catheter hepatic artery embolization for liver cysts in autosomal dominant polycystic kidney disease. Am J Kidney Dis. 2007; 49:744-752. [PubMed: 17533017]

69. Park HC, Kim CW, Ro H, et al. Transcatheter arterial embolization therapy for a massive polycystic liver in autosomal dominant polycystic kidney disease patients. J Korean Med Sci. 2009; 24:57-61. [PubMed: 19270814]

70. Dimitrakov J. A road map to biomarker discovery and validation in urological chronic pelvic pain syndrome. J Urol. 2008; 179:1660-1661. [PubMed: 18343423]

71. Hewitt SM, Dear J, Star RA. Discovery of protein bio-markers for renal diseases. J Am Soc Nephrol. 2004; 15:1677-1689. [PubMed: 15213255]

72. Chapman AT, VE, Perrone R, Steinman T, et al. The HALT Polycystic Kidney Disease Trials: Design and Implementation. C J A S N. 2010 
73. Akinci D, Turkbey B, Yilmaz R, Akpinar E, Ozmen M, Akhan O. Percutaneous treatment of pyocystis in patients with autosomal dominant polycystic kidney disease. Cardiovasc Interv Radiol. 2008; 31:926-930.

74. Akinci D, Akhan O, Ozmen M, et al. Long-term results of single-session percutaneous drainage and ethanol sclerotherapy in simple renal cysts. Eur J Radiol. 2005; 54:298-302. [PubMed: 15837413]

75. Lee YR, Lee KB. Ablation of symptomatic cysts using absolute ethanol in 11 patients with autosomal-dominant polycystic kidney disease. Korean J Radiol. 2003; 4:239-242. [PubMed: 14726641]

76. Uemasu J, Fujihara M, Munemura C, Nakamura E, Kawasaki H. Cyst sclerotherapy with minocycline hydrochloride in patients with autosomal dominant polycystic kidney disease. Nephrol Dial Transplant. 1996; 11:843-846. [PubMed: 8671906]

77. Kim SH, Moon MW, Lee HJ, Sim JS, Kim SH, Ahn C. Renal cyst ablation with n-butyl cyanoacrylate and iodized oil in symptomatic patients with autosomal dominant polycystic kidney disease: Preliminary report. Radiology. 2003; 226:573-576. [PubMed: 12563157]

78. Uemasu J, Fujiwara M, Munemura C, Tokumoto A, Kawasaki H. Effects of topical instillation of minocy cline hydrochloride on cyst size and renal function in polycystic kidney disease. Clin Nephrol. 1993; 39:140-144. [PubMed: 8462201]

79. Singh I, Mehrotra G. Selective ablation of symptomatic dominant renal cysts using $99 \%$ ethanol in adult polycystic kidney disease. Urology. 2006; 68:482-487. [PubMed: 17010722]

80. Kim SH, Cho JY. Cyst ablation using a mixture of N-butyl cyanoacrylate and iodized oil in patients with autosomal dominant polycystic kidney disease: the long-term results. Korean $\mathrm{J}$ Radiol. 2009; 10:377-383. [PubMed: 19568466]

81. Sakuhara Y, Kato F, Abo D, et al. Transcatheter arterial embolization with absolute ethanol injection for enlarged polycystic kidneys after failed metallic coil embolization. J Vasc Interv Radiol. 2008; 19:267-271. [PubMed: 18341960]

82. Masue N, Katoh S, Itoh S, et al. Renal transcatheter arterial embolization for autosomal dominant polycystic kidney disease: Report of two cases. Hinyokika Kiyo. 2005; 51:741-745. [PubMed: 16363706]

83. Rehman J, Landman J, Andreoni C, McDougall EM, Clayman RV. Laparoscopic bilateral hand assisted nephrectomy for autosomal dominant polycystic kidney disease: Initial experience. J Urol. 2001; 166:42-47. [PubMed: 11435819]

84. Jenkins MA, Crane JJ, Munch LC. Bilateral hand-assisted laparoscopic nephrectomy for autosomal dominant polycystic kidney disease using a single midline HandPort incision. Urology. 2002; 59:32-36. [PubMed: 11796276]

85. Bendavid Y, Moloo H, Klein L, et al. Laparoscopic nephrectomy for autosomal dominant polycystic kidney disease. Surg Endosc. 2004; 18:751-754. [PubMed: 15026905]

86. Desai PJ, Castle EP, Daley SM, et al. Bilateral laparoscopic nephrectomy for significantly enlarged polycystic kidneys: A technique to optimize outcome in the largest of specimens. Br J Urol. 2008; 101:1019-1023.

87. Desai MR, Nandkishore SK, Ganpule A, Thimmegowda M. Pretransplant laparoscopic nephrectomy in adult polycystic kidney disease: A single centre experience. Br J Urol. 2008; 101:94-97.

88. Binsaleh S, Al-Enezi A, Dong J, Kapoor A. Laparoscopic nephrectomy with intact specimen extraction for polycystic kidney disease. J Endourol. 2008; 22:675-680. [PubMed: 18324899] 


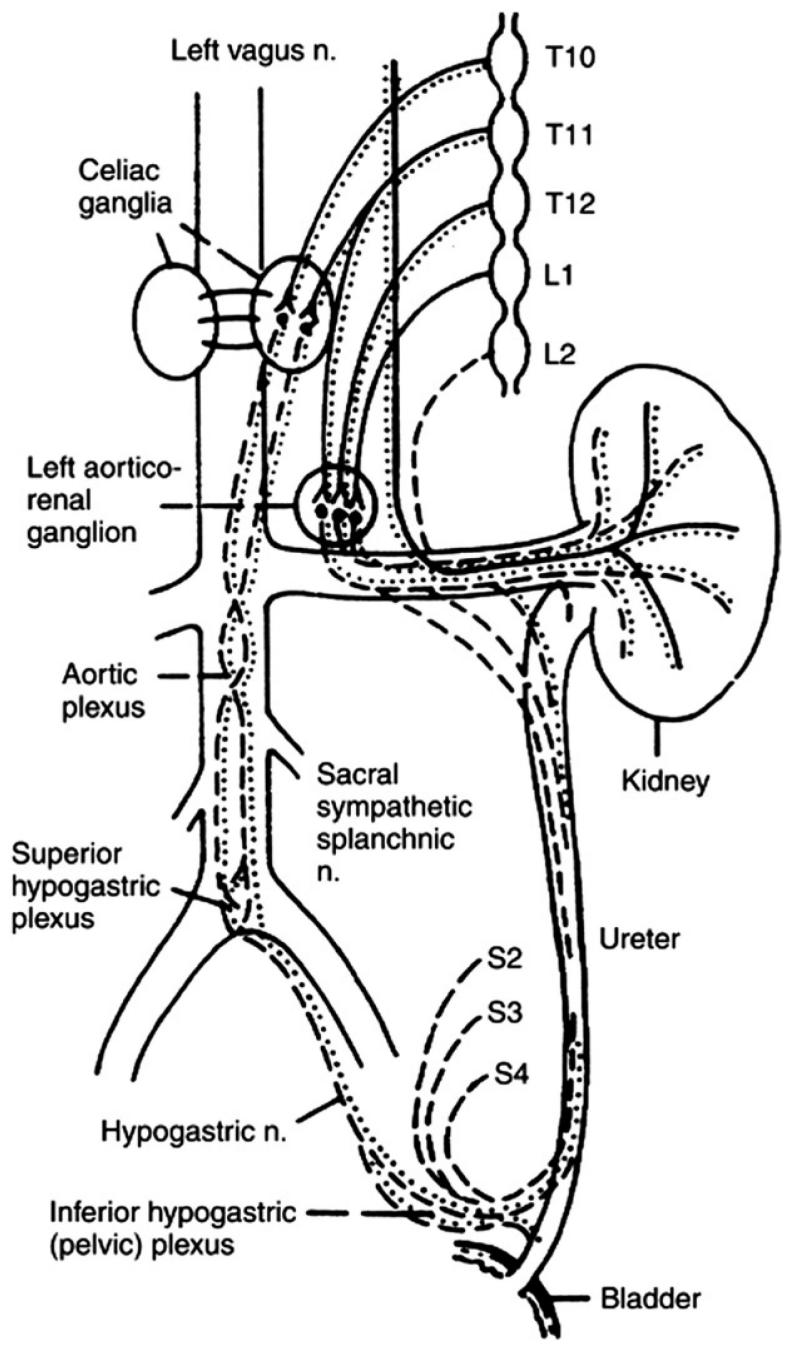

Figure 1.

The sympathetic, parasympathetic and sensory innervation of the kidney. Sympathetic fibers from the spinal cord run to the sympathetic chain and, thereafter, via the splanchnic nerves, synapse in the celiac ganglion. The splanchnic nerves lie medial to the sympathetic trunk over the bodies of the thoracic vertebra. Solid line; sympathetic component; dotted line parasympathetic nerve supply; dashed line-afferent sensory fibers and these travel with the autonomic nerves. (By permission of Mayo Foundation for Medical Education and Research, as adapted from Ansell ${ }^{12}$ ). 

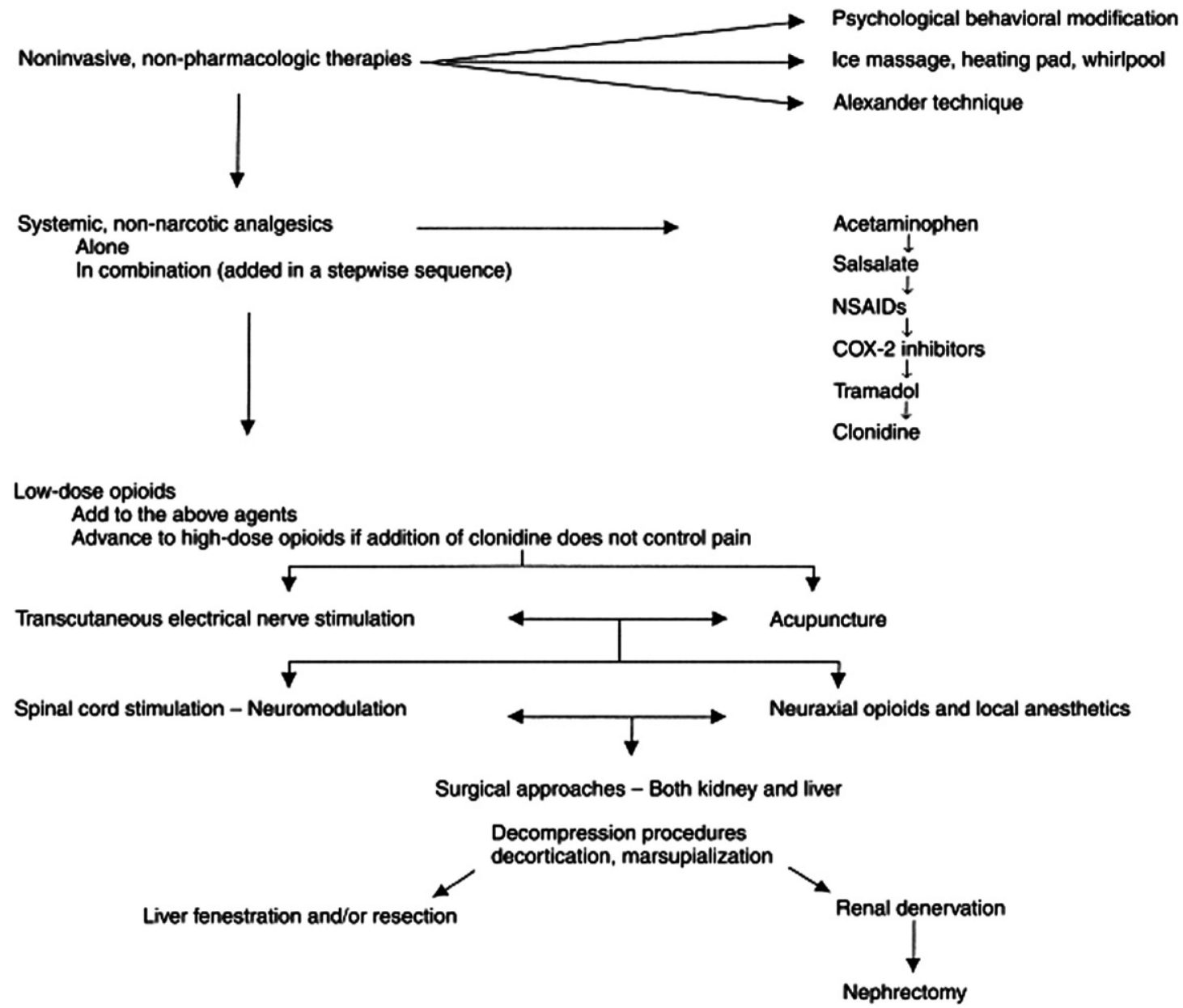

Figure 2.

A sequential approach to pain management in polycystic kidney disease patients. The first step is to set expectations that pain may not be "cured," but there will be adaptations that will allow the patient to adjust to the chronic pain. Combining different modalities may be needed for refractory pain. (Reprinted with permission.1). 


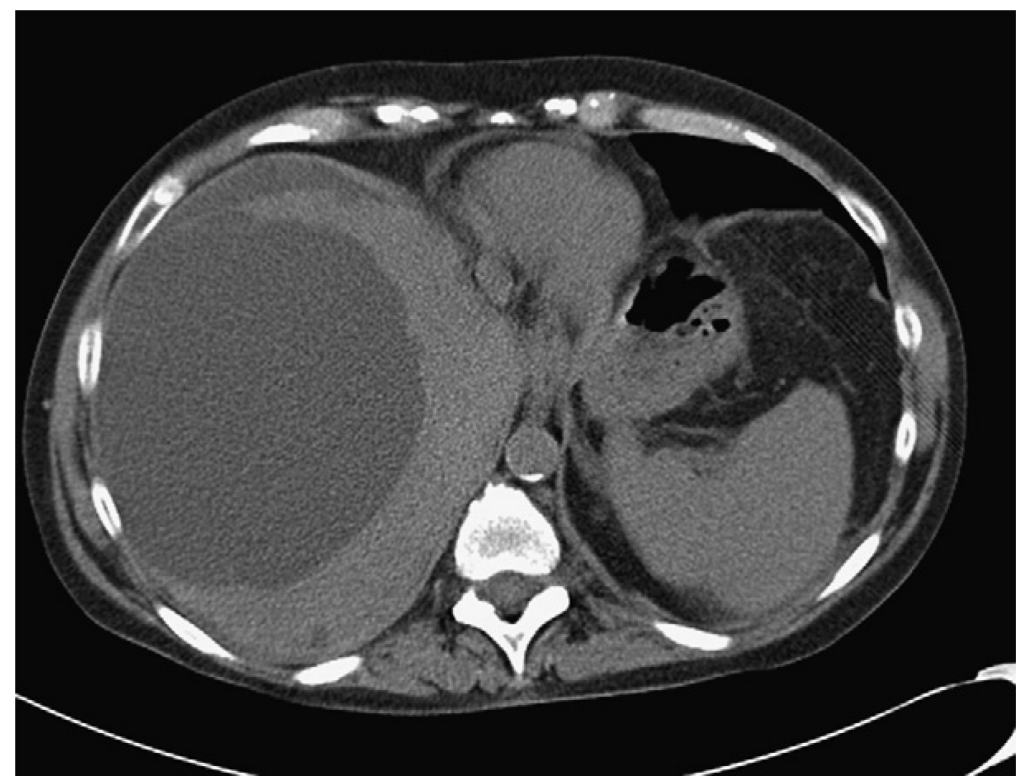

Figure 3.

A CT scan of a 59-year-old patient with ADPKD with a dominant right lobe of liver cyst (13 $\mathrm{cm}$ in diameter). This patient was managed initially with aspiration of the large cyst shown here. No sclerosis was performed, and the cyst fluid refilled the cyst within 3 months enlarging to $17-\mathrm{cm}$ diameter. She then underwent laparoscopic right-lobe cyst fenestration and remained symptom free for a further 16 months. 


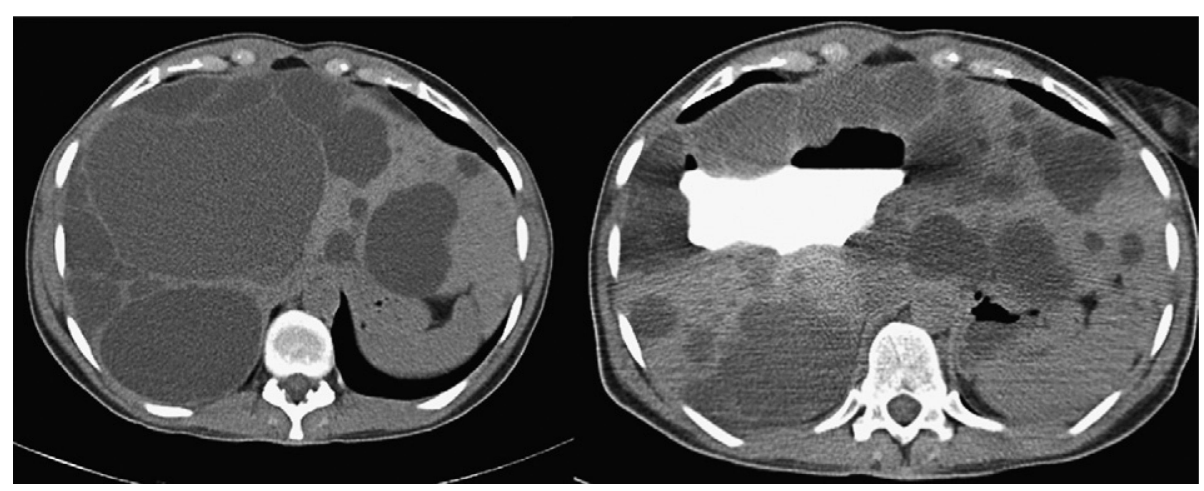

Figure 4.

The CT scan shows location of larger right upper lobe liver cyst in a 39-year-old female patient with autosomal dominant polycystic liver disease. Images are shown (before and after) $1,100 \mathrm{~mL}$ of fluid was aspirated from the cyst without apparent complication under CT guidance; $150 \mathrm{~mL}$ of saline and contrast were then reinjected into the cyst (second image). Imaging of the entire liver was then performed that showed no evidence of extravasation from the cyst or connection to the biliary tree. This material was then removed from the cyst, and $20 \mathrm{~mL}$ of alcohol were used to sclerose the liver cyst over a 15-minute period. Alcohol was then removed from the cyst. The patient tolerated the procedure well. 

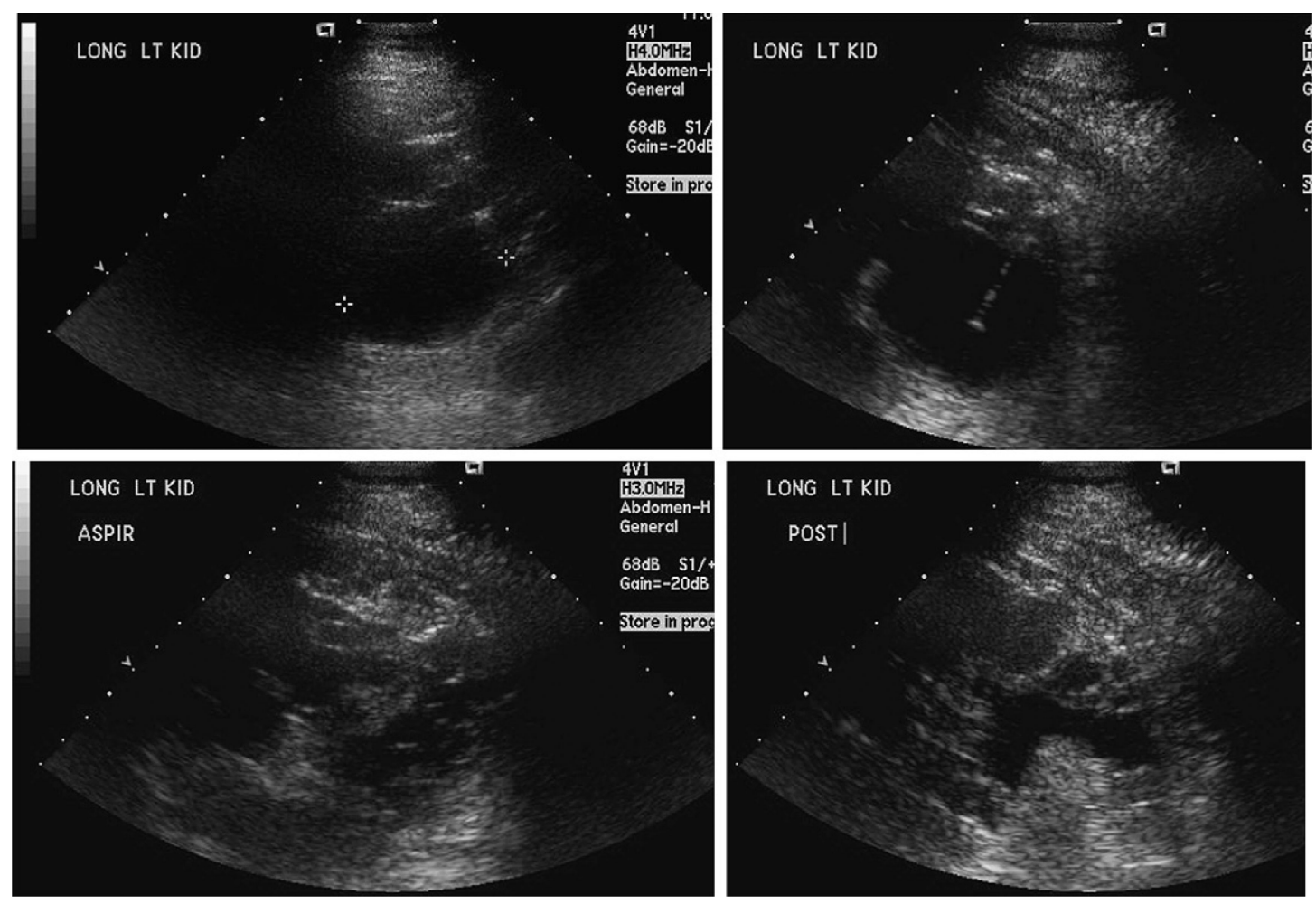

Figure 5.

Ultrasound-guided left kidney cyst aspiration and cyst sclerosis for kidney pain in an opiatedependent 39-year-old man with ADPKD and chronic left kidney pain. He had cyst fenestration surgery 1 year prior where 156 cysts removed from the left kidney. Subsequently, aspiration the largest cyst was drained on the left kidney, and the procedure was a failure in terms of pain. He reported exacerbations of acute pain due to cyst rupture occurring averaging monthly. The dominant 6-cm cyst in the posterior superior aspect of the left kidney seemed to correlate with this patient's left kidney pain (marked with cursors 11 ). Using ultrasound guidance, sterile technique, local anesthetic (1\% lidocaine containing bicarbonate), and intravenous sedation, a catheter was advanced into this cyst and $\sim 50 \mathrm{~mL}$ of yellow fluid was removed. Next, $20 \mathrm{~mL}$ of $95 \%$ sterile ethanol was instilled into the cyst under real-time ultra-sound guidance. This was left in place for 8 minutes, at which point a total of $40 \mathrm{~mL}$ of fluid was removed, completely decompressing the cyst. 
Table 1

Starting doses of selected short and long acting opioids for chronic non-cancer pain ${ }^{a}$

\begin{tabular}{|c|c|c|c|c|}
\hline \multirow[b]{2}{*}{ Drug } & \multicolumn{2}{|c|}{ Oral administration } & \multirow[b]{2}{*}{ Duration of effect (h) } & \multirow[b]{2}{*}{ Plasma half-life (h) } \\
\hline & Dose (mg) $b$ & Frequency (h) & & \\
\hline Codeine & $15-60$ & $3-6$ & $4-6$ & 3 \\
\hline Fentanyl & $100-200 \mu \mathrm{g}$ & $6^{c}$ & 0.5-1 (IV), 72 (TD), 2-4 (TM) & 3.7 \\
\hline Hydrocodone & $2.5-10.0$ & $3-6$ & $4-8$ & $2.5-4.0$ \\
\hline Hydromorphone & $2-4$ & $3-4$ & $4-5$ & $2-3$ \\
\hline Levorphanol & $2-4$ & $6-8$ & $6-8$ & $12-16$ \\
\hline Methadone & $5-10$ & $6-8$ & $4-6$ & 24 \\
\hline Morphine & $15-30$ (IR) & 3-4 (IR) & $3-6$ & $2.0-3.5$ \\
\hline Oxycodone & 10 (CR), 5-10 (IR) & 12 (CR), 3-6 (IR) & 8-12 (CR), 3-4 (IR) & $2.5-3.0$ \\
\hline Oxymorphone & 10 (IR), 5-10 (ER) & 4-6 (IR), 12 (ER) & $3-6$ & $7.0-9.5$ \\
\hline Propoxyphone & $65-100$ & 4 & $4-6$ & $6-12$ \\
\hline Tramadol & $50-100$ (IR), 100 (ER) & 4-6 (IR), 24 (ER) & 4-6 (IR), 24 (ER) & $5-7$ \\
\hline
\end{tabular}

Data from references 1,32 , and 34 .

Copyright permission Argoff, CE et al. Mayo Clin Proc, 84: 602-12, 2009.

${ }^{a} \mathrm{CR}=$ controlled-release; $\mathrm{ER}=$ extented release; IR = immediate-release; $\mathrm{IV}=$ intravenous; $\mathrm{TD}=$ transdermal; $\mathrm{TM}=$ transmucosal.

$b$ Doses are given in milligrams unless otherwise indicated.

${ }^{c}$ Not more than 4 doses per day. 


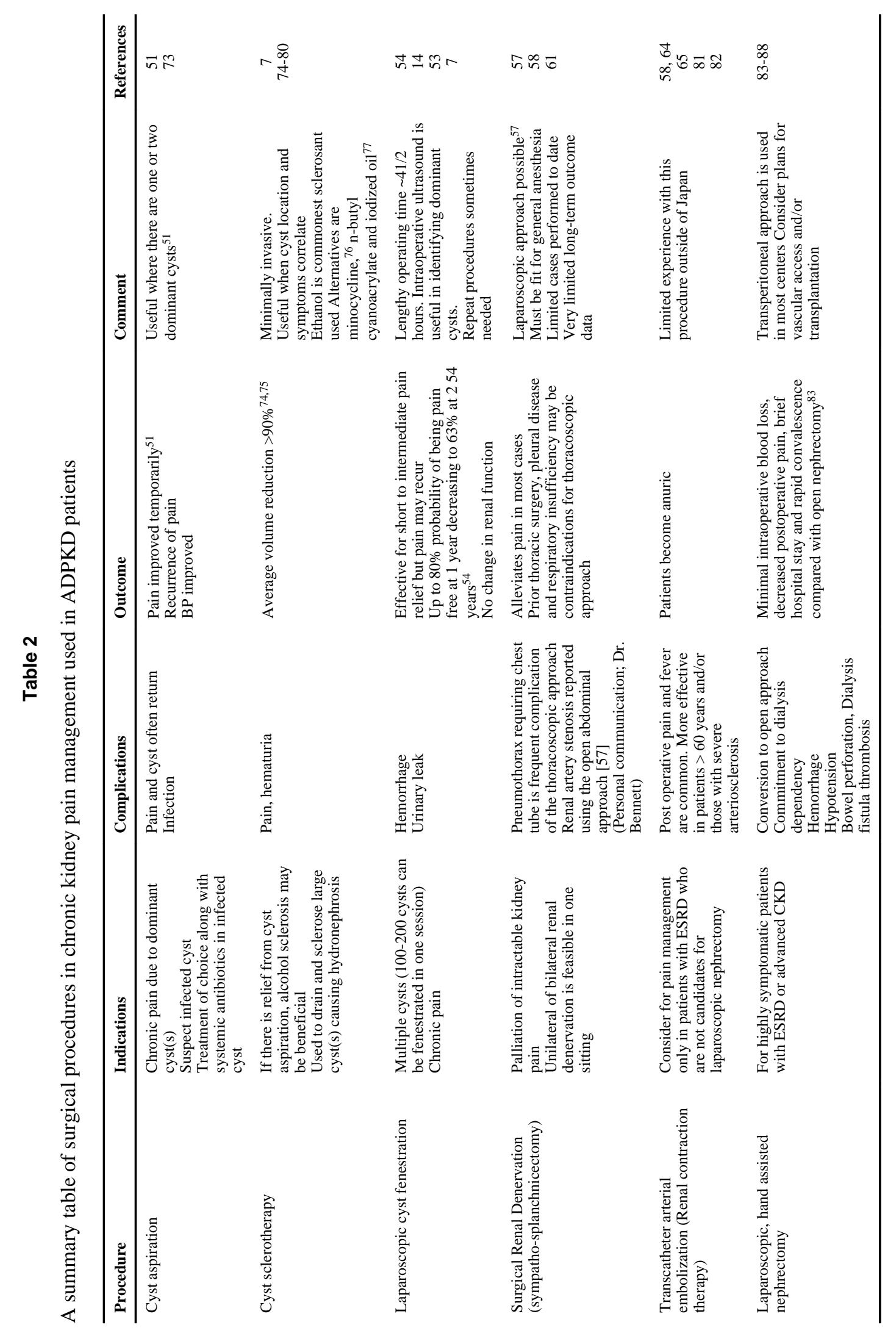

